\title{
FARMERS' PERCEPTION ON CLIMATE CHANGE AND ECOLOGICAL HAZARDS IN RIU AND RAPTI WATERBASIN, CHITWAN, NEPAL
}

\author{
H.P.Regmi ${ }^{1}$, P.P.Regmi ${ }^{2}$, J.P.Dutta ${ }^{3}$ and D.R.Dangol ${ }^{4}$
}

\begin{abstract}
A survey research was done to study the farmers' perception on climate change and ecological hazards in Riu and Rapti water basin, Chitwan, Nepal. Altogether 120 households, 60 from each water basin in Riu and Rapti were selected randomly for the study. Pre-tested interview, direct observation, focus group discussion as well as secondary data from Department of Hydrology and Meteorology (DHM), Kathmandu were used to collect the required information. Majority of the farmers' perceived the change in climatic condition in their locality in terms of increase in hotter days, decrease in colder days, variability in the number of rainy days, decrease in rainfall duration, increase in amount and intensity of rainfall, late onset and shift of usual monsoon pattern, prolonged occurrences of dry spells, decrease water level in the river as compared to the past decades. Farmers prioritized the floods/riverbank cutting (61.7\%) and drought (63.4\%) hazards for obtaining immediate solution/adaptation strategies in Riu water basin; and for drought (60\%) and loss of wetland and declining water source (45\%) in Rapti water basin. Analysis of the climatic data (last 42 years for rainfall and last 30 years for temperature) showed the increasing trend of annual rainfall (6.83 $\mathrm{mm}$ per year) and those of both maximum and minimum temperature $\left(0.019{ }^{\circ} \mathrm{C}\right.$ per year and $0.069^{\circ} \mathrm{Cper}$ year, respectively). These analyses strongly support the farmers' perception about the climate change and for which immediately effective adaptation mechanism is required.
\end{abstract}

Key words: Adaptation. Climatic data, Floods/Riverbank cutting, Trend analysis

\section{INTRODUCTION}

Climate change is the global issue at and one of the most complex challenges that humankind has to face in the coming decades. It poses an increasing threat to the sustainability of agricultural production and livelihood strategies of poor and rural people worldwide. Nepal's temperature has increased by $1.70 \mathrm{C}$ during last 30 years (1975 to 2005) with the average temperature increased by $0.06{ }^{\circ} \mathrm{C}$ per year (Shrestha et al., 1999) and in particular, $0.04{ }^{\circ} \mathrm{C} /$ year in Terai and $0.08{ }^{\circ} \mathrm{C} /$ year in Himalayas. A study on aggregated precipitation and average temperature of five meteorological stations (Dhangadi, Surkhet, Pokhara, Kathmandu and Dhankuta) showed an increasing trend in both temperature and total precipitation in Nepal (Gurung, 2007a). In the recent years, the intensity, amount and distributions of rainfall have been changed in unpredictable manner. The number of the rainy days is decreasing by $0.8 \%$ day per year, however, it is estimated that the rainfall is increased by $13 \mathrm{~mm}$ per year. Consequently, the river flow is increasing at the rate of $1.48 \mathrm{~m}^{3} / \mathrm{s}$ per year (Regmi, 2007). Higher increase in summer river flow provides the evidence for faster glacial melt due to higher summer temperature.

Climate change has serious impact on agriculture and livelihood of farming community. Local communities from the Chitwan experienced the change in the climate in recent years (Gurung and Bhandari, 2008). Farmers are experiencing change in temperature and precipitation pattern, in parallel; they are also following some adaptation strategies to respond changing climate in their livelihood and at farm level.

\footnotetext{
1 Agriculture Officer, Pilot Project on Climate Resileince:BRCH-AMIS, Kathmandu, hariregmi14@gmail.com, 9845196993

2 Professor, AFU

3 Professor, AFU

$4 \quad$ Natural History Museum, TU, Kathmandu
} 
In this regard, this study was conducted to assess the farmers' perception on climate change and ecological hazards, and answered the questions, whether they perceived climate change or not in terms of change in number of hotter days, number of colder days, number of rainy days, duration, amount and intensity of the rainfall, onset of usual monsoon and dry spells as compared to the past decades. Furthermore, this study analyzes the climatic data of Rampur station, Chitwan for last 30 years to verify the farmers' perception.

\section{MATERIALS AND METHODS}

The study was conducted in the central region of inner Terai of Nepal. Chitwan district was purposively selected for the study. The study focuses to explore the perception of marginal farmers on climate change and their adaptation strategies. For this, two water basins namely Riu and Rapti were selected with the consultation of the community level and district level organizations. These settlements are occupied with indigenous farming communities like Tahru, Bote, Majhi and severely affected with the floods and riverbank erosion. The study sites were selected because ethnic and marginal community resides in these areas and are the vulnerable sites in terms of floods and riverbank cutting. Altogether 120 respondents, sixty from each water basin were selected randomly for the study.

The local communities and resource poor farmers who have long experience in autonomous adaptation of the study area were the primary source of information. The pre-tested interview schedule was administered to the respondents to collect primary information. These data were supplemented by information obtained from focus group discussion, direct observation, transect walk and key informant interview. Participatory methods were used to collect data, to share experience and knowledge of vulnerable communities towards climate change. Primary data were collected through interview schedule. Information collected from the field survey was coded first and entered into the computer. Data entry and analysis were done by using computer software package; Statistical Package for Social Science (SPSS 16 version) and Microsoft Excel. Perceptions of farmers on the change of climatic variables and climatic hazards over the time were analyzed by estimating frequency, percentage, charts and diagrams. Climatic data were analyzed by using trend analysis with the following formula:

$$
\begin{aligned}
Y=b_{1} x+C & \\
\text { Where, } Y & =\text { Climatic parameter (Rainfall and temperature) } \\
x & =\text { Time horizon (years) } \\
b_{1} & =\text { Coefficients } \\
C & =\text { Constant }
\end{aligned}
$$

\section{RESULTS AND DISCUSSIONS}

\section{FARMERS' PERCEPTION ON CHANGE IN NUMBER OF COLDER DAYS, HOTTER DAYS, OCCURRENCES OF} HAILSTORMS, WATER LEVEL IN THE RIVERS AS COMPARED TO PAST YEARS

The study revealed that, $58.3 \%$ respondents perceived the decrease in number of colder days and 73.3\% respondent perceived increase in number of hotter days as compared to past years. Farmers viewed that days become hotter and hotter as compared to the past years (Fig 1). They reported that water level in the river was continuously deepening in the Riu water basin, and were unable to irrigate their field due to the loss of canal as a result of the deepening of the Riu Khola. However during the few days in rainy season, there was huge floods covering wider area and affecting the crops and community settlement. Farmers also perceived the heavy occurrences of hailstorms in 
past years, but within the 3-4 years, there was no occurrences of such hailstorms at all and even if occur but with very small size.

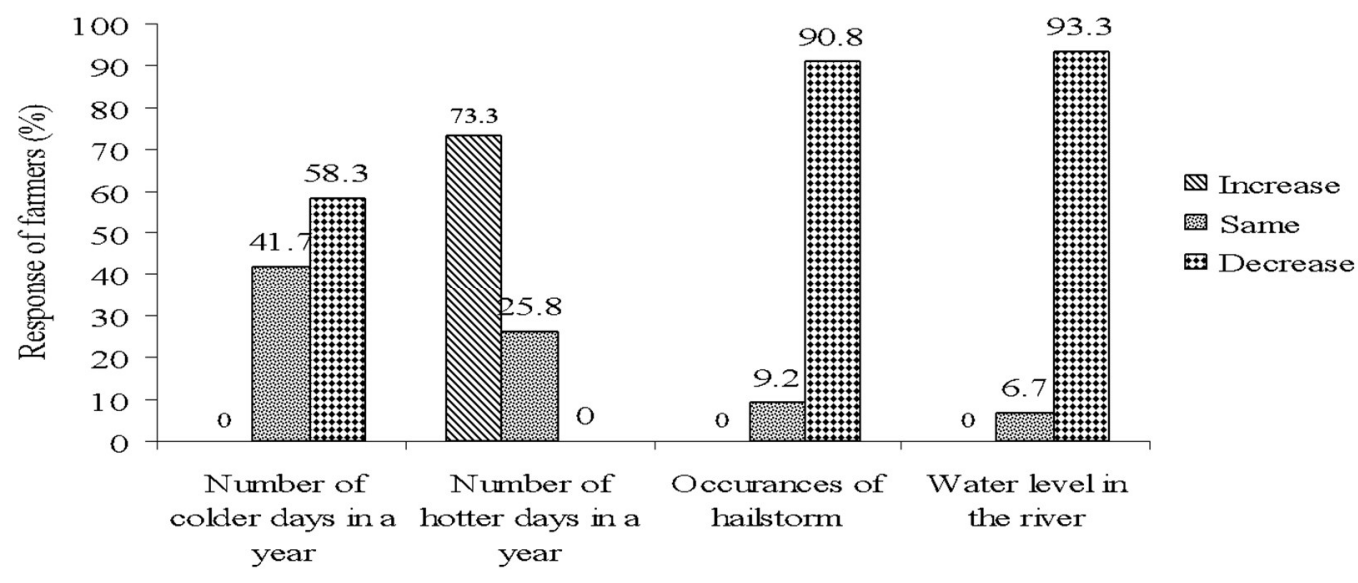

Figure 1: Farmers' perception on climate change

\section{FARMERS PERCEPTION ON CHANGE ON RAINFALL PATTERN}

There was wide variation in the rainfall pattern as compared to the past. Majority of the farmers, $83.3 \%, 75 \%$ and $23.24 \%$ perceived decrease in duration, number of rainy days and amount of rainfall, respectively, in rainy season (June to September) as compared to the past (Figure 2).

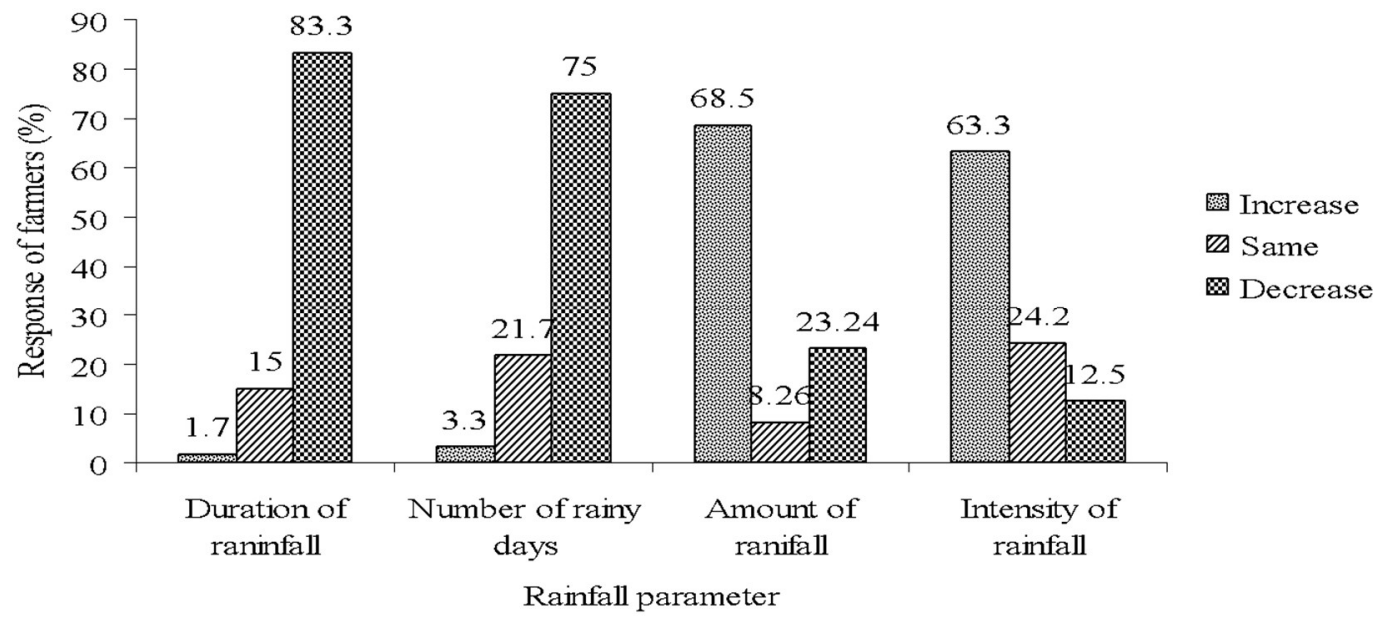

Figure 2: Farmers' perception about the change in rainfall parameter (In rainy season)

Untimely rainfall was the major reason for late planting of many crops including maize and rice. As the other parameters of rainfall was decreasing, $63.3 \%$ farmers' perceived the increased intensity of rainfall in recent years, such a more intense rainfall was major reason for occurrences of floods and riverbank erosion. Gurung (2007a) also reported that, $95 \%$ farmers noticed the erratic rainfall as an indicator of climate change in Chitwan. 
The study revealed the similar response of farmers about the trend of winter seasonal rainfall except its intensity as of the rainy seasonal rainfall. Majority of the respondents reported decline in number of rainy days, amount and intensity of the rainfall in other season (October - May) as compared to the past (Figure 3). Farmers' reported the decline in winter rainfall was one of the important factor for declining yield of winter crops like wheat, mustard, and different types of vegetables.

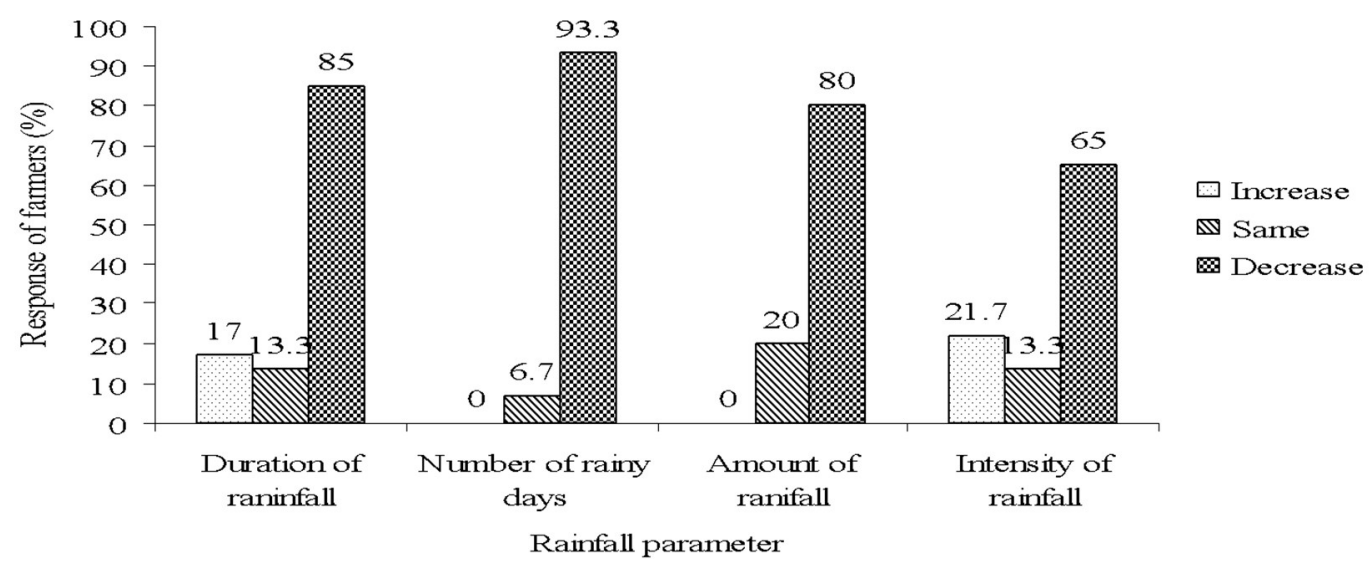

Figure 3: Farmers' perception about the change in rainfall parameter (October-May)

\section{FARMERS PERCEPTION ABOUT BEGINING OF MONSOON AND OCCURANCES OF DRY SPELLS}

Timely onset of monsoon is the major governing factor for improving agricultural production. Late onset of monsoon is responsible for declining crop production by delay in planting and shorter growth period of the crops. 93.3\% of respondents reported the late onset of monsoon as compared to the past (Table 1). $85.8 \%$ of farmers responded the prevalence of longer period drought as compared to the past. Gurung (2007a) also reported that $95 \%$ farmers have used drought and erratic rainfall as an indicator for changing climate in Chitwan. They recall the drying of their maize crops and rice seedlings in the year 2009 due to the late onset of monsoon and pronounced dry spells and harvested poor yield.

Table 1: Farmers' perception about the onset of monsoon and occurrences of dry spells in Riu and Rapti water basin (2010)

\begin{tabular}{cccc}
\hline \multicolumn{2}{c}{ Beginning of monsoon as compared to past } & \multicolumn{2}{c}{ Occurrences of dry spells as compared to past } \\
\hline Timing of monsoon & Response & Duration of drought & Response \\
\hline Earlier & $0(0)$ & Longer period & $103(85.8)$ \\
Same & $8(6.7)$ & Same & $17(14.2)$ \\
Later & $112(93.3)$ & Shorter period & $0(0)$ \\
Total & $120(100.0)$ & Total & $120(100)$ \\
\hline
\end{tabular}

\footnotetext{
${ }^{*}$ Figure in parenthesis indicate the percentage
} 


\section{MAJOR CLIMATE INDUCED HAZARDS AND THEIR PRIORITISATION}

Key informant survey provides the severity of three major climate induced hazards in the settelement of Riu and Rapti water basin. Major climatic hazards were;

A. $\quad$ Floods and riverbank cutting

B. Drought

C. Loss of wetlands and water sources

Rapti River and Riu Khola were responsible for occurrences of monsoon flooding in the study area. Farmers were asked for ranking the timing of carrying out effective adaptation and coping measures to respond the climatic hazard. Drought $(63.4 \%)$ and floods/riverbank cutting $(61.7 \%)$ hazards required urgent and immediate solution in Riu water basin as compared to the loss of wetland and declining water resources (Figure 4). Similarly, floods/riverbank cutting (38.3\%) and loss of wetland/water resources $(33.3 \%)$ required the medium term solution in Riu water basin. The settlement in Riu water basin was very close to the river and in every year, the river approaches towards the community settlement, so they are under the vulnerable situation in terms of flood risk.

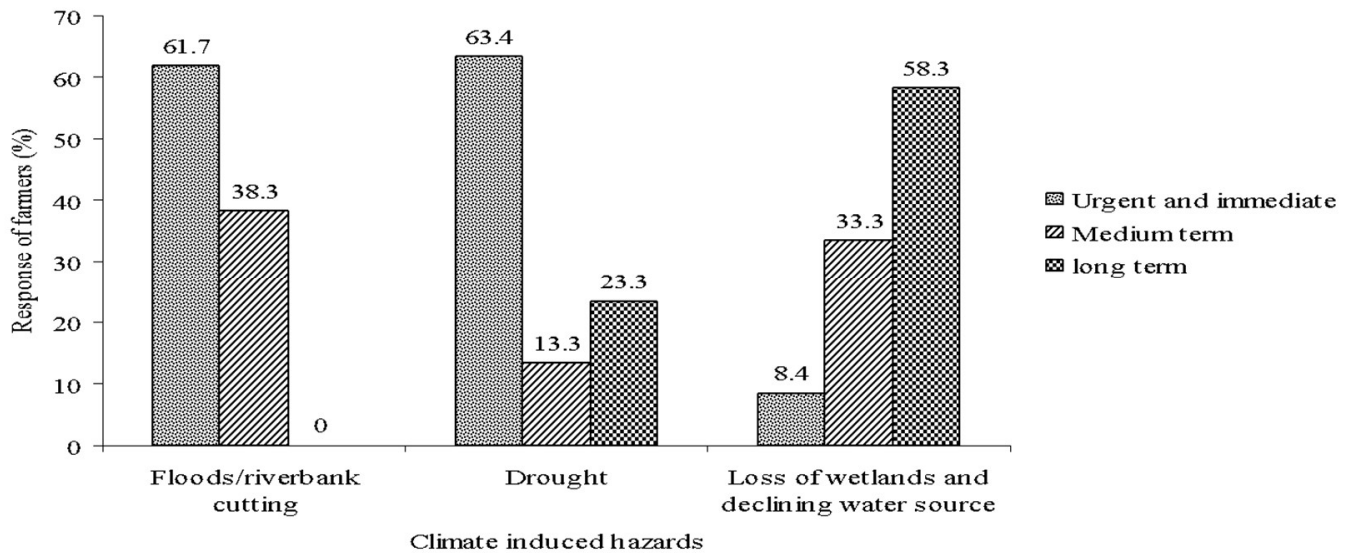

Figure 4: Prioritization and timing of solution for climatic hazards in Riu water basin (2010)

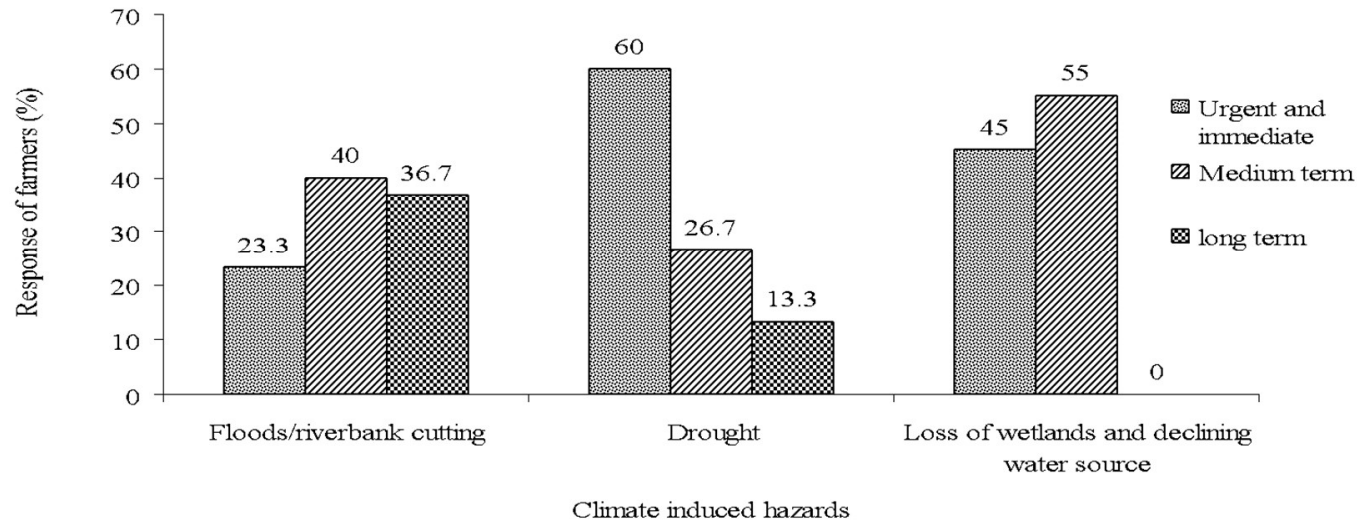

Figure 5: Prioritization and timing of solution for climatic hazards in Rapti water basin (2010) 
The study revealed that, drought $(60 \%)$ and loss of wetlands/declining water source $(45 \%)$ hazards required urgent and immediate solution, similarly loss of wetland/water sources $(55 \%)$ and floods/riverbank cutting (40\%) hazards required medium term solution in Rapti water basin (Figure5). Lower percentage of the farmers prioritized floods and riverbank cutting as compared to the Riu, because of the more distance between Rapti river and the community settlement. They faced greater problem of drought, declining wetlands and water recharge. ECOS (2002) reported the increment in park area from $932 \mathrm{sq}$. $\mathrm{km}$ to $1182 \mathrm{sq}$. km due to addition of cultivated private land as a result of shift in river course towards community settlement.

\section{ANALYSIS OF THE RAINFALL DATA OF RAMPUR STATION FOR LAST 42 YEARS (1968- 2009)}

Analysis of the rainfall data of last 42 years of the Rampur station showed the irregular pattern of rainfall over the year.

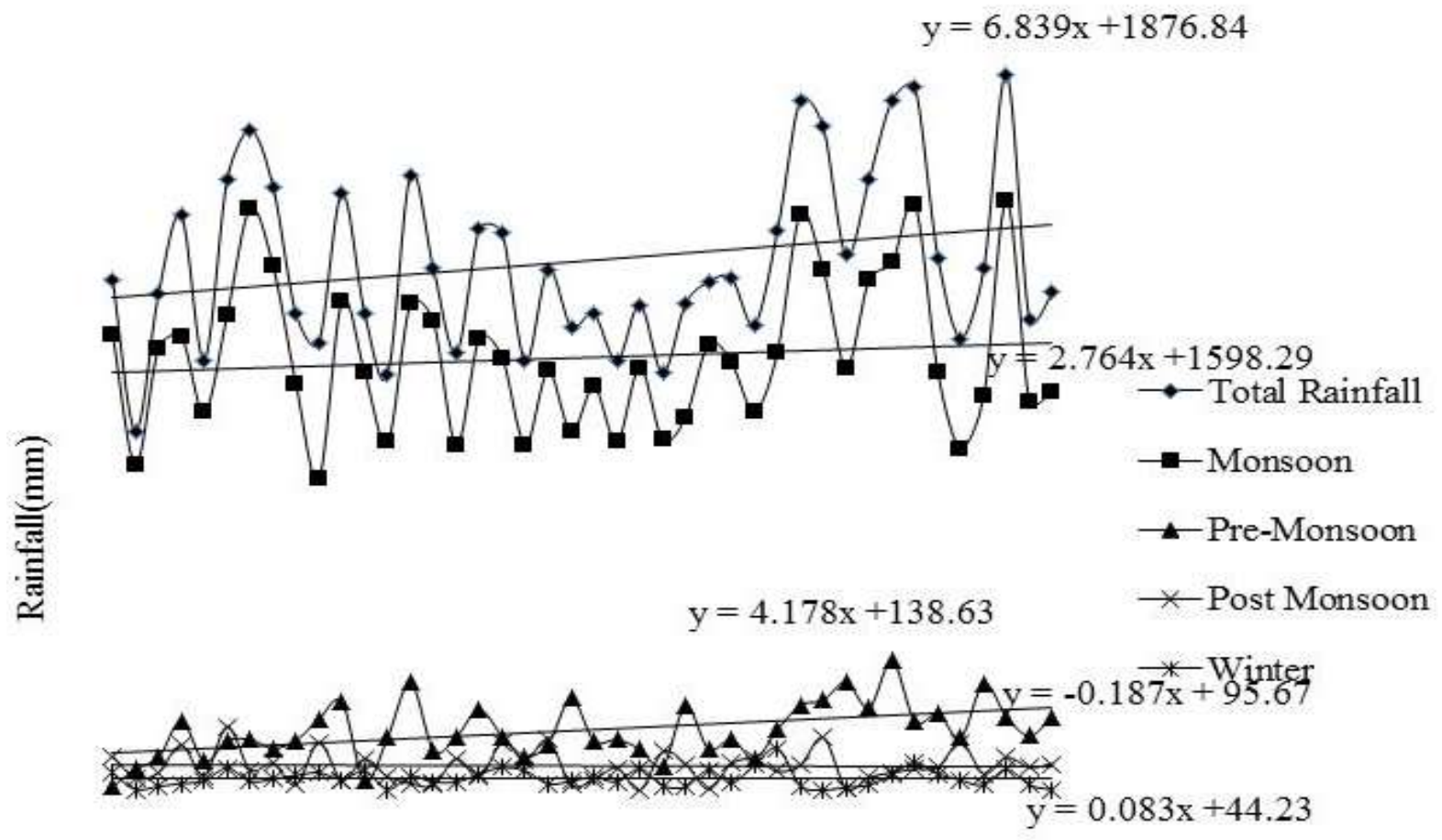

Year

Figure 6. Trend analysis of rainfall data of Rampur, Chitwan (1968-2009)

Total rainfall, pre-monsoon (March-May), monsoon (June-September), post monsoon (OctoberNovember) and winter (December-February) rainfall varied across the time horizon. Post-monsoon rainfall showed the decreasing trend but the analysis of the all other rainfall indicated increasing trend over the years (Figure 6). All the seasonal rainfall declined for last two years (2007 and 2008), so, farmers were unable to cultivate their crops in right time and their cropping calendars were shifted. Analysis of the climatic data strongly supports the farmer's perception. Farmers in such scenario couldn't predict the usual rainfall pattern and they were compelled to changed their cropping calendar. The trend analysis showed the $6.83 \mathrm{~mm}$ per year increment in total rainfall in 
Rampur station, which was higher than the increase in all Nepal average precipitation trend by 5.17 $\mathrm{mm}$ per year as reported by Gurung (2007b).

\section{ANALYSIS OF THE MONSOON PATTERN IN CHITWAN IN LAST 10 YEARS}

Occurrences of the usual monsoon were shifted towards August instead of June- July in recent years as compared to the past in Chitwan.

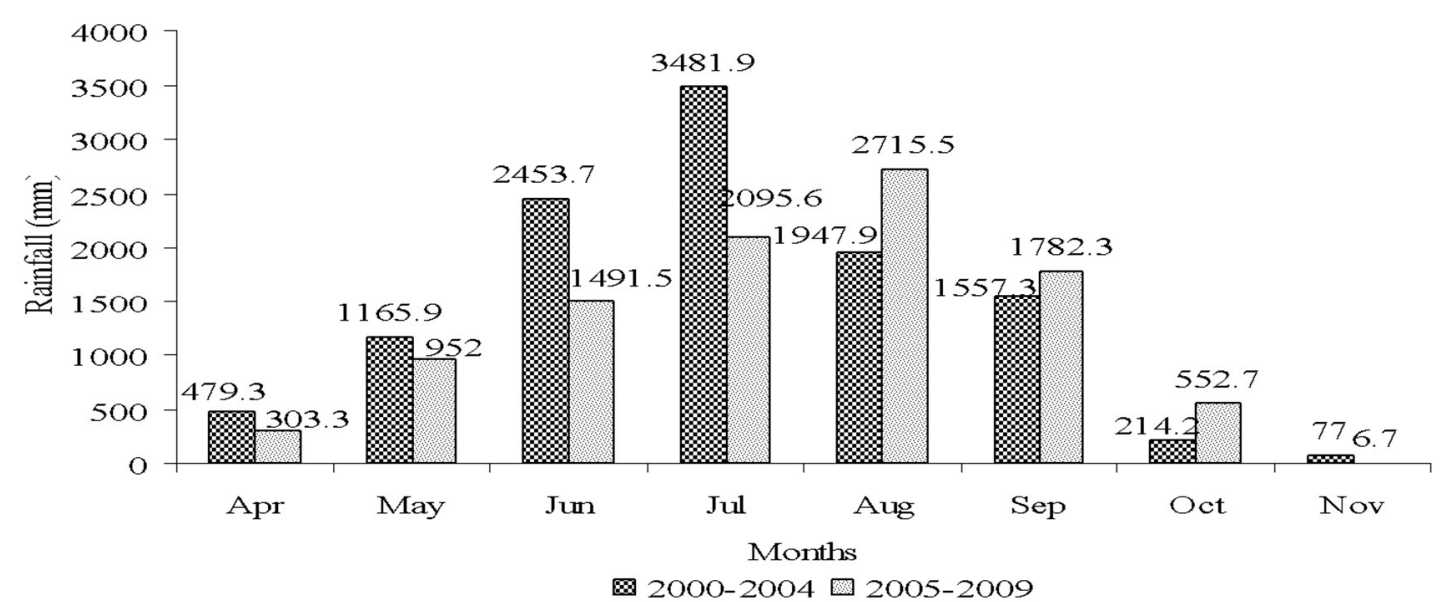

Figure 7: Analysis of the monsoon pattern in Rampur, Chitwan in last 10 years

Total July Precipitation (3481.9mm) was higher for 2000-2004 but August precipitation (2715.5mm) was higher for 2005-2009. Rainfall was declining from month of April to July and then after increases up to October in recent years (2005-2009) than that of 2000-2004. Analysis of the rainfall data strongly support the farmers' perception on higher amount of rainfall in later month of monsoon period in recent year (2005-2009) than that of earlier years (2000-2004) which was responsible for change in crop rotation and cropping calendar as perceived by the farmers.

ANALYSIS OF THE CHANGE IN MAXIMUM AND MINIMUM TEMPERATURE FOR LAST 30 YEARS IN RAMPUR STATION, CHITWAN(1980-2009)

Analysis of the maximum and minimum temperature of last 30 years of the Rampur station showed that both minimum temperature $(P<0.01)$ and maximum temperature $(P<0.1)$ were increased significantly over the time.

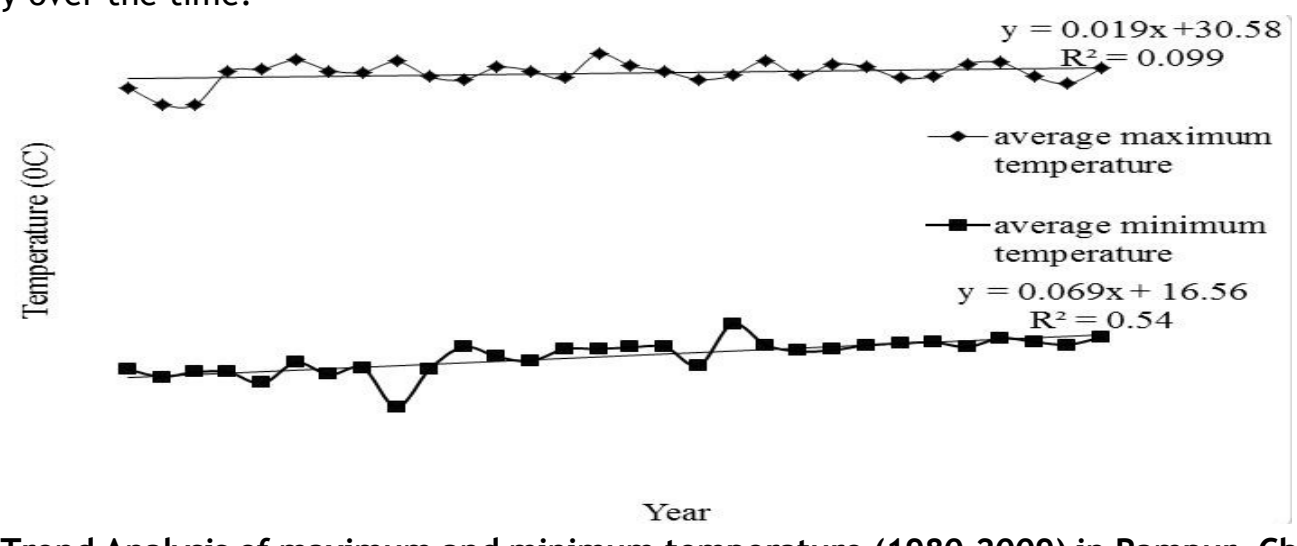

Figure 8: Trend Analysis of maximum and minimum temperature (1980-2009) in Rampur, Chitwan 
Trend analysis showed that maximum temperature increased by $0.019{ }^{\circ} \mathrm{C}$ per year and minimum temperature was increased by $0.069^{\circ} \mathrm{C}$ per year (Figure 8). Average maximum temperature increased in lower rate than national average of $0.042^{\circ} \mathrm{C}$ per year (Baidya and Karmacharya, 2007). Trend analysis of temperature strongly supports the farmers' perception as that of hotter summer and less cold winter as compared to the past.

\section{CONCLUSION}

Based upon the study it was concluded that most of the farmers perceived the change in climatic parameters at present in terms of change in rainfall pattern, duration, timing, intensity, onset of monsoon, and change in summer and winter temperature in terms of hotness and coldness and which was supported by the analysis of the climatic data. Farmers realized the change in climate and their usual farming practices. Farmers should be aware about the climate change and promote them to practice improved farming packages. It is important to develop and plan sustainable adaptation strategies and make farmers capable to cope with emerging impacts of climate change and its related hazards in forthcoming years.

\section{ACKNOWLEDGEMENTS}

The farmers in the study area for their supports and cooperation during the study period were acknowledged.

\section{REFERENCES}

Baidya, K. S. and J. Karmacharya. 2007. Observed and future climate change in Nepal. In: Climate Change and Human Health: Potential Impact, Vulnerability and Adaptation in Nepal. Proceeding of National Workshop held at Kathmandu, Nepal. 19-21 December, 2007. pp. 22-23.

ECOS. 2002. Conflict and Unity between National Park and People: A Study (Nepali version). Ecological Services Center. Ganesh Chapakhana, Narayangarh, Chitwan.

Gurung, G. B. 2007a. Watershed management approach for climate change adaptation. Available in https://www.mtnforum.org/rs/counter_docdown.cf. Retrieved on 19 th July, 2009.

Gurung, G. B. and D. Bhandari. 2008. An integrated approach to climate change adaptation. Magazine on Low External Input and Sustainable Agriculture. 24(4):6.

Regmi, B. R. 2007. Climate change risk and vulnerability in Nepal.Nepal Up in Smoke?In: Time for Action on Climate Change. Local Initiative for Biodiversity, Research and Development and Clean Energy Nepal. pp. 6-8.

Shrestha, A. B., C. P. Wake, P. A. Mayewski, and J. E. Dibb. 1999. Maximum temperature trends in the Himalaya and its vicinity: an analysis based on temperature records from Nepal for the period 1971 1994. Journal of Climate. 12: 2775-2789. 